\title{
Relación Estado/nación, modelo de desarrollo económico y sistema de partidos en Chile: breve revisión histórica para tratar de entender un cambio de época
}

\author{
Daniel Bello Arellano \\ Universidad Arturo Prat, Iquique, Chile. Email: dbello@unap.cl
}

\begin{abstract}
Resumen: El presente artículo revisa las etapas por las que transitó el Estado chileno a partir de la década de 1930, particularmente en relación a las mutaciones del rol que desempeñó en la conducción de la economía nacional, y el impacto de aquellos cambios en la vinculación entre partidos políticos y sociedad, o en un sentido más amplio, entre Estado y nación. Observamos dos etapas claramente diferenciadas, la primera caracterizada por la constitución del Estado en pieza clave del modelo de desarrollo económico e importante organizador de la sociedad, tarea -esta última- propiciada por la acción mediadora de los partidos políticos, los cuales establecieron profundos lazos con diversas organizaciones sociales, permitiendo la canalización de demandas y la distribución de beneficios. La segunda etapa, que se empieza a desarrollar a partir del quiebre democrático de 1973, muestra el repliegue del Estado y la imposición del mercado como eje central del modelo económico y como principal mecanismo de distribución de bienes y servicios. El retorno a la democracia -en 1990- estuvo marcado por esta realidad "mercado-céntrica" y por la nueva estructura institucional ideada durante la dictadura militar, lo que moldeó la reestructuración de sistema de partidos y obligó a cambiar las estrategias de interacción entre partidos políticos y sociedad, privilegiándose el marketing político y la utilización de medios de comunicación masivos por sobre la relación directa con las disminuidas organizaciones sociales. Esta revisión histórica puede ayudar a entender la actual crisis de representación y participación que se observa en Chile.
\end{abstract}

Palabras clave: Estado-nación, modelo de desarrollo económico, partidos políticos, sistema de partidos, Chile

\section{State/nation relationship, economic development model and party system in Chile: brief historical review as an attempt to understand a change of time}

\begin{abstract}
This article reviews the stages through which the Chilean State moved from the 1930s onward, particularly concerning the transformations in the role it played managing the national economy, and the impact these changes had in the link between political parties and society or, in a broader sense, between State and nation. We observe two clearly defined stages. The first characterized by the constitution of the State as a key element of the economic model development and an important organizer of society; task -this last one- propitiated by the mediating action of political parties, which established deep bonds with different social organizations, enabling the channelling of demands and distribution of benefits. The second stage, which began with the breakdown of democracy in 1973, shows the State's withdrawal and the imposition of the market as the focal point of the economic model as well as the main mechanism behind the distribution of goods and services. The return to democracy -in 1990- was characterized by this "marketcentric" reality and by the new institutional structure conceived during the military dictatorship. This shaped the party system reorganization and forced a shift in interaction strategies between political parties and society, prioritizing political marketing and the use of new mass media over a direct relationship with the now deflated social organizations. This historical review may help understand the current representation and participation crisis seen today in Chile.
\end{abstract}

Key words: State/nation, economic development model, political parties, party system, Chile

\section{Relação Estado / nação, modelo de desenvolvimento econômico e sistema partidário no Chile: uma breve revisão histórica para tentar entender uma nova era}

Resumo: O presente artigo analisa os estágios pelos quais transitou o Estado chileno a partir de 1930 particularmente em relação às mudanças no papel que desempenhou na condução da economia nacional eo impacto dessas mudanças na relação entre os partidos políticos ea sociedade, ou num sentido mais amplo, entre o Estado ea nação. Observou-se duas fases distintas, a primeira caracterizada pela constituição do estado como ator fundamental de desenvolvimento económico e organizador importante da sociedade, uma tarefa-esta última, movidos pela ação mediadora dos partidos políticos, que estabeleceu laços profundos com diversas organizações sociais, permitindo canalizar as demandas e distribuição de benefícios. A segunda etapa, que começa a se desenvolver a partir do colapso da democracia em 1973, mostra o recuo do Estado e à imposição do mercado como central para o modelo econômico como o principal 
mecanismo de distribuição de bens e serviços. O retorno à democracia em 1990 - foi marcada por esta realidade "mercado-centrica" e por a nova estrutura institucional concebida durante a ditadura militar, que moldou a reestruturação do sistema partidário e forçou a mudar as estratégias de interação entre os partidos políticos ea sociedade, com ênfase em marketing político e uso da mídia de massa sobre o relacionamento com as reduzidas organizações sociais. Esta revisão histórica pode ajudar a compreender a atual crise da representação e participação mostrado no Chile.

Palavras-chave: Estado-nação, modelo de desenvolvimento econômico, partidos políticos, sistema partidário, Chile

$$
* * *
$$

\section{Introducción}

Hoy, poco más de dos décadas después de renacida la democracia en Chile -a contar de las primeras elecciones presidenciales postdictadura (diciembre de 1989)- resulta interesante e importante, para el análisis del funcionamiento del sistema político, del sistema de partidos y de cada una de las organizaciones que lo conforman, tener presente la gran variedad y profundidad de cambios experimentados por el Estado y la sociedad nacional desde aquella "oscura" mañana de septiembre -38 años atrás- en que los militares "accedieron" al poder. Complejas transformaciones económicas, políticas y culturales que germinaron a partir de las semillas esparcidas por los "vientos del Norte", depositadas en lo más profundo de la grieta ocasionada por la fractura institucional que significó el Golpe de Estado de 1973.

La violenta desarticulación y reestructuración multidimensional que vivió Chile a partir de entonces (1973) - con el apoyo de Estados Unidos, en un contexto de Guerra Fría- “destruyó no sólo la democracia sino el modelo de Estado y la relación Estado/nación” (Castells, 2005). Siguiendo las directrices norteamericanas, mediante la liberalización de la economía y la privatización del sector público, el mercado reemplazó al Estado como ente-mecanismo distribuidor de beneficios. Así, la histórica relación clientelar entre Estado y nación $^{1}$-que permitió la integración de las clases medias burocráticas y los sectores populares (Castells, 2005)- dio paso a la competencia "libre" y asimétrica entre individuos por los recursos disponibles en el mercado, reconfigurando el rol del Estado y desbaratando las redes de interacción entre partidos políticos y sociedad civil.

Esto fue producto de la instauración -durante los primeros años de la dictadura militar- de un modelo de desarrollo económico capitalista-liberal, inspirado en las elucubraciones abstractas de teóricos neoclásicos, remozado por académicos norteamericanos y europeos, que a la larga, gracias a la "Revolución Conservadora" de Thatcher y Reagan -en los 80's-, el crecimiento del mercado global y la caída de los socialismos reales -y el consecuente desprestigio de las "opciones antagónicas" de desarrollo planificado- se impuso a nivel planetario, ocasionando un impacto cuya onda expansiva traspasaría con mucho lo netamente económico.

Fue el -por algunos- proclamado triunfo de la ideología liberal, que marcó, según Francis Fukuyama (1990), el fin de la historia, "el punto final de la evolución ideológica de la humanidad", que a la postre ocasionó, en el ámbito local, -sean o no veraces los postulados de aquel intelectual neoconservador- un "consenso sustantivo" en ciertos macro fines (Moulián, 2002) y la consecuente contracción del espectro político-ideológico en el sistema de partidos chileno, al tiempo que obligó a replantear el rol del Estado y el modo de articulación entre partidos y sociedad (Roberts, 2002).

Este trabajo, teniendo como fin entregar algunos elementos para la construcción de una atalaya que permita observar el presente desde una mejor perspectiva, propone hacer una sumaria revisión histórica del rol desempeñado por el Estado chileno - a partir de la tercera década del siglo XX- en el desarrollo económico del país y en la articulación de la sociedad nacional, y las transformaciones y cambios experimentados por el sistema de partidos, considerando el periodo dictatorial -inserto en un proceso de transformaciones globales marcado por fuertes pugnas ideológicas- como una etapa de inflexión que define un antes y un después en la relación Estado/nación y en la constitución del sistema de partidos chileno. 


\section{Transformaciones económicas, sociales y políticas: del modelo Estado-céntrico en democracia, al mercado-céntrico en dictadura}

Como mencionamos anteriormente, las reformas impuestas por la dictadura militar afectaron profundamente la relación Estado/nación, y en consecuencia las estrategias de interacción entre partidos políticos y sus bases de apoyo social. Hasta entonces, es decir hasta septiembre de 1973, el modelo de desarrollo económico Estado-céntrico ${ }^{2}$ propició, en especial en los "sistemas de partido de movilización obrera" como el chileno (Roberts, 2002), una estrecha vinculación entre organizaciones políticas y organizaciones sociales de diversa índole.

\section{a. El Estado toma las riendas del desarrollo}

Fue a partir de la Gran Depresión de $1929^{3}$, y en mayor medida hacia fines de la década del $30^{4}$, que el Estado empieza a asumir roles protagónicos en el desarrollo de la economía nacional, a través de la promoción y participación directa en el emergente proceso de Industrialización por Sustitución de Importaciones (Correa et al., 2001). La crisis internacional favoreció la concreción de acuerdos políticos y consensos transversales que permitieron dar este giro hacia una economía protegida y orientada al mercado interno $^{5}$ (Correa et al., 2001). Pero la presencia del Estado no se dejó sentir sólo en el ámbito económico. Mediante una fuerte -y creciente- inversión fiscal en salud, educación, vivienda, etc. el aparato público asumió un «papel rector en el concierto de la vida nacional" (Correa et al., 2001). Todo esto estrechó los vínculos entre el Estado - distribuidor de beneficios-, los partidos políticos -que asumieron un importante rol en la canalización de aquellos beneficios y las demandas sociales- y las organizaciones de la sociedad civil, particularmente aquellas que contaban con un mayor "poder sindical"6 -es decir los sindicatos mejor organizados y más influyentes ${ }^{7}$ - (Correa et al., 2001).

Tiempo más tarde, luego de la crisis de mediados de los 50's -que a decir de Gilbert (1997) profundizó las contradicciones entre clases al interior de la sociedad nacional-, y concluido el gobierno del derechista Jorge Alessandri Rodríguez (1958-1964) -el que intentó con magros resultados "resolver la crisis de acumulación originada por el estancamiento del proceso de industrialización sustitutiva, a través de la implementación de un programa de estabilización" (Gilbert, 1997), lo que significó una derrota para el liberalismo económico y propició el descrédito (social y político) de la empresa privada-, el Estado asume un protagonismo aún mayor en la articulación social y la conducción de la economía nacional, en parte presionado por la creciente participación política favorecida por las reformas electorales del '50, '58, '62 y $70^{8}$ (Fontaine, 1993).

\section{b. Reformas impulsadas por el Estado: expropiación de los medios de producción y promoción y crecimiento de las organizaciones sociales}

A juicio de Fontaine (1993), el lento crecimiento de la producción y el empleo -por algunos atribuido, en aquel entonces, a la mala disposición para la inversión del sector privado- en tensión con la necesidad de los partidos de atender a las demandas de los nuevos electores, generó un agudo debate político-ideológico de donde salió victoriosa la idea de que "ante la fatiga del sistema imperante, todo tenía que cambiar" (Fontaine, 1993).

De este modo, a partir del '64 y en especial desde el '70, el Estado asume nuevos desafíos incrementando su responsabilidad en la distribución de beneficios. Gracias al paulatino proceso de expropiación de los medios de producción ${ }^{10}$, -el "Estado empresario" y "empleador" (Garretón, 1995)- buscó asegurar la inversión y acelerar el crecimiento con el fin de disponer de los recursos para la "necesaria" expansión del gasto fiscal.

Para sustentar en el tiempo tal proyecto -bastante controversial y polarizador-, el ejecutivo se abocó a la tarea de consolidar una base de apoyo social-electoral ${ }^{11}$, fortaleciendo sindicatos y creando nuevas instancias de participación, lo que generó un gradual debilitamiento de las tradicionales vías institucionalizadas de interacción entre partidos políticos ${ }^{12}$, volviendo más directas y cruciales las relaciones

entre partidos y las organizaciones sociales ${ }^{13}$, y trasladando, a la larga, la contienda político-ideológica a las calles. 
Durante el mandato del democratacristiano ${ }^{14}$ Eduardo Frei Montalva (1964-1970), la puesta en marcha de numerosos proyectos gubernamentales, dentro de los que destacan la Reforma Agraria, el programa de "Promoción Popular"15, la "chilenización del cobre", y la ampliación y el mejoramiento de los servicios públicos, permitió acrecentar el protagonismo del Estado ${ }^{16}$ como organizador social y rector de la economía. Gracias a las mencionadas medidas se pudo abrir un espacio para la participación de vastos sectores de la población -antes excluidos- en el debate público nacional, a través de los nuevos sindicatos -obreros y campesinos-, las organizaciones vecinales, las asociaciones de padres de familia, etc. creados/as con el apoyo del ejecutivo.

Hacia fines de la década del 1960, una nueva crisis económica avivó las controversias políticoideológicas en torno al modelo de desarrollo y al manejo de las finanzas públicas, ocasionando una profunda división -incluso al interior de la Democracia Cristiana ${ }^{17}$ - entre quienes veían indispensable profundizar las reformas iniciadas el '64, y quienes por el contrario creían necesario contrarrestarlas.

En estas condiciones, y luego de una feroz pugna electoral (1970) -en la que se hicieron patentes los conflictos ideológicos que dividían a parte importante de la sociedad- Salvador Allende, representante a la izquierdista alianza Unidad Popular (UP), llegó al poder con el apoyo del 36,3\% de los electores ${ }^{18}$. Desde un primer momento buscó cumplir lo prometido en su programa de gobierno, el cual consignaba -entre otras cosas- la profundización de las reformas iniciadas por Frei y "la nacionalización de la Gran Minería del Cobre, de los monopolios industriales estratégicos, del comercio exterior, de los bancos, los seguros y las grandes empresas en sectores claves de la economía" (Correa et al., 2001). Al no contar -el gobierno- con suficiente apoyo en el Congreso, se vio obligado a recurrir a distintas estrategias que le permitieron bordeando la institucionalidad que se comprometió irrestrictamente a respetar- mantener el curso de lo propuesto. La compra de acciones de las empresas en cuestión y los llamados "resquicios legales"19 fueron algunos de los caminos seguidos con este fin. La vorágine expropiatoria agudizó las tensiones políticas y sociales y propició aún mayores niveles de participación popular a través de la acción directa ${ }^{20}$-a favor y en contra de las medidas gubernamentales-, promovida y articulada muchas veces por el propio gobierno y los partidos políticos.

En este contexto, de alta polarización, con un sistema de partidos anquilosado -producto de las pugnas ideológicas-, y de profunda crisis económica -generada en cierta medida por las presiones externas propias de la Guerra Fría-, los militares encabezados por el general Pinochet, desatendiendo a la llamada "Doctrina Schneider" "21 intervinieron y quebraron el régimen democrático, se instalaron en el poder, y permanecieron en el por 17 años, tiempo que fue suficiente para -parafraseando a Castells (2005)-, "destruir y reformular el modelo de Estado y la relación Estado/nación".

\section{c. El giro hacia el mercado en la dictadura militar}

Como vimos, la etapa comprendida entre fines de la década de 1930 y septiembre de 1973, se caracterizó por el rol central que asumió el Estado en el ordenamiento y conducción de la economía nacional, y en la articulación y organización de la sociedad, sea a través de la acción netamente redistributiva de las primeras dos décadas (1938-1958), o mediante una más comprometida participación directa en la producción, generación de puestos de trabajo y redistribución de la propiedad en los últimos nueve años ${ }^{22}$ (1964-1973), siempre en el marco de un modelo económico "volcado hacia adentro", que giraba en torno a la industria nacional, con un alto intervencionismo estatal, tanto en lo referido a la creación de barreras arancelarias para el control de las importaciones, como en el control de salarios y precios, etc. (Fontaine, 1993).

El régimen militar transformó no sólo el orden político -al "destruir la democracia" (Castells, 2005)-, sino que reformuló el modelo de Estado y el de desarrollo económico. Al adoptar un modelo de libre mercado -"neoliberal"-, a partir del año $1975^{23}$, el gobierno de facto modificó el rol del Estado en la economía, siguiendo -como explica Garretón (1995)- tres vías principales: a) "las privatizaciones, tanto de empresas como de servicios sociales; b) la desregulación estatal de precios y de las actividades económicas en general, así como también de la fuerza de trabajo ${ }^{24}$; y c) una política de apertura al comercio exterior, con incentivos y facilidades para la diversificación de las exportaciones y un facilitamiento para la inversión extranjera". 
De este modo, se enfrentó la crisis -agravada por la caída del precio del cobre y la subida del precio del petróleo- no con un moderado y tibio programa de estabilización, sino más bien con una contra-reforma "revolucionaria", -cargada ideológicamente-, posibilitada por el autoritarismo militar, y la desarticulación de los partidos políticos y los sindicatos, "que desmanteló el régimen intervencionista creado durante tres o cuatro décadas de políticas redistributivas" (Fontaine, 1993).

El mercado pasó a ser, así, el centro articulador de la sociedad nacional, conduciendo la economía mediante la autorregulación y la "libre" competencia-, y asumiendo el rol -abandonado por el Estado- de distribuidor de beneficios, gracias a la reducción dramática del gasto público y a la privatización de los servicios sociales. Esto provocó un distanciamiento en la relación Estado/nación, antes propiciada -o mediada- por la interacción entre partidos políticos y organizaciones sociales, y generó más bien una vinculación (competencia) directa entre individuos -consumidores- "libres" ${ }^{25}$, dentro del marco establecido por las (hoy naturalizadas ${ }^{26}$ ) leyes de mercado.

El "Estado redistributivo-empresario-empleador", que permitió integrar a vastos sectores de la población (Castells, 2005; Garretón, 1995) -a través del empleo público y el gasto (inversión) social, etc.-, dio paso a un Estado represor, excluyente, preocupado principalmente de restablecer la confianza de los empresarios, prestamistas y grandes grupos económicos extranjeros y nacionales vinculados con aquellos espantados por "la amenaza socialista del período precedente"27 (Garretón, 1995)-, por medio de las mencionadas privatizaciones, la implantación de severas medidas fiscales y monetarias sacadas, al menos en apariencia, de un recetario del Fondo Monetario Internacional (Fontaine, 1993), la desarticulación -violentadel hasta entonces poderoso movimiento sindical, la eliminación del sistema de representación partidaria (Garretón, 1995), la persecución de líderes, militantes, simpatizantes de los partidos de izquierda $-\mathrm{y}$ de todo aquel contrario al régimen-, la construcción de un marco institucional propicio, tendente a evitar la fragmentación y polarización social y política del pasado, y a perpetuar la presencia militar en las altas esferas deliberativas, etc.

Así, el Estado ocupó un nuevo sitial, comenzó a interpretar un nuevo papel, en el marco de un complejo escenario mundial, siguiendo el guión escrito por el (neo) liberalismo económico occidentalestadounidense -que por aquel entonces mantenía una pugna ideológica planetaria con el "marxismo actualizado" (Fukuyama, 1990)-.

Los cambios experimentados por el país en los años de dictadura -no sólo los que afectaron al Estado y al modelo económico, sino también los complejos cambios culturales ${ }^{28}$, derivados en gran medida de la imposición del nuevo modelo de desarrollo y la subsecuente vinculación directa entre individuos y mercado-, reforzados por el "triunfo" a nivel mundial del liberalismo económico ${ }^{29}$-con la caída del bloque soviético- y el vertiginoso proceso de globalización económica y cultural, establecieron las limitantes, tanto concretas como sicológicas, que condicionaron -una vez retomada la senda democrática- la reconstitución del sistema de partidos, y dificultaron la reconstrucción de las redes de interacción entre las organizaciones políticas y una sociedad civil cada vez más atomizada y organizacionalmente dispersa (Roberts, 2002).

\section{Democracia, mercado y sistema de partidos: convergencia ideológica y distanciamiento político/social}

Luego de las crecientes tensiones y disputas, y la gradual polarización político-ideológica de los 60`s y 70‘s; luego de la violenta reacción militar de 1973 -muertos, desaparecidos y exiliados de por medio-, y la traumática sustitución del modelo económico-; Luego de la (supuesta) efectividad demostrada por el sistema al superar la profunda crisis de 1983-84, y el poco cuestionado éxito de la economía a partir de 1985 (Fontaine, 1993), nadie (salvo alguno que otro) se mostró entusiasmado con la idea de desandar el camino recorrido hacia la liberalización económica. Considerando además, que las energías se concentraron -a partir de 1990, durante el primer gobierno postdictadura- en pavimentar la pedregosa senda democrática, maltrecha por tanques y bombas, y rediseñada -por los militares y sus allegados antes de dejar el poder- con ingeniosos ardides que dificultaron y hasta hoy dificultan (sino imposibilitan) que -la democracia- se desarrolle plenamente -libre de enclaves institucionales (Garretón, 1995, 2003; González, 2001)-, no es de extrañar que el modelo económico llamado neoliberal -o fundamentalista de mercado- se haya visto inalterado por el 
cambio de régimen, al igual que el accionar socialmente restringido y pro-mercado del Estado. De hecho, el gestionar bien el modelo se convirtió en imperativo para sustentar la frágil renaciente democracia.

Por esto, el reestructurado sistema de partidos debió adaptarse - del 90 en adelante- a una realidad diametralmente distinta a la de los 60‘s o 70's. Con nuevas reglas de juego establecidas por el mercado y un reconfigurado rol del Estado; una coyuntura signada por la apertura económica y el realismo político ante la victoria del neoliberalismo, por las complejidades culturales de la sociedad individualista, y por las restricciones generadas por la Constitución de 1980 -y algunos “ingeniosos" ajustes normativos de último minuto- (González, 2001).

\section{a. Convergencia ideológica: reducción del espectro político intra-sistema}

Producto de aquella adaptación al nuevo contexto, el mapa político-ideológico chileno cambió en forma sustancial. La polaridad -que “devino en polarización sólo en la fase 1970-1973" (Moulián, 2002)característica del anterior sistema de partidos -vale decir la amplia gama ideológica (con posiciones antagónicas) contenida en el espectro político e incluida en el sistema de partidos- desapareció, ya sea por la acción excluyente del sistema electoral binominal ${ }^{30}$, o por la "migración" de alguno de los partidos "polares" hacia posiciones, digamos, "ecuatoriales". Este último fue el caso del Partido Socialista de Chile (PS), que según Moulián (2002)- por un asunto de realismo político, consecuencia -creemos- del golpe propiciado por la historia, abandonó las posiciones radicales que lo llevaron a la intransigencia en tiempos de la Unidad Popular $^{31}$-sustituyendo, de paso, su tradicional imaginario marxista por uno socialdemócrata- (Moulián, 2002).

Para hacer frente a la nueva estructura institucional ${ }^{32}$, los partidos - manteniendo su independencia- se agruparon en dos grandes coaliciones que no dieron cabida a las fuerzas revolucionarias anti-sistema contrarias al modelo económico - las que antes fueron importantes partícipes del juego político-. El Partido Comunista (PC) -por ejemplo-, histórico aliado de socialistas (PS) y radicales (Partido Radical Social Demócrata) en "frentes populares", al mantener su impronta marxista revolucionaria y crítica al neoliberalismo, quedó marginado del sistema, sin opciones reales de acceder al poder. En resumidas cuentas, se puede decir - siguiendo las ideas de Moulián (2002)- que se produjo una convergencia ideológica, un "consenso sustantivo" en ciertos macro fines, como en la idea "del papel central de la iniciativa privada y el papel sólo regulador del Estado, la apertura de la economía al exterior como norma general, el rol decisivo del mercado, la necesidad de flexibilidad laboral, etc." (Moulián, 2002). La convergencia se produjo en posiciones ideológicas de derecha, y las ideas de izquierda quedaron relegadas a los extramuros del sistema de partidos.

\section{b. Distanciamiento político/social: el producto de la difícil tarea de representar}

Por otro lado, -también producto de tal adaptación- como se ha dicho varias veces a lo largo de este texto, el estrecho vínculo entre partidos políticos y sociedad civil -construido durante el largo periodo en que el Estado tomó las riendas del desarrollo y desempeñó un «papel rector en el concierto de la vida nacional" (Correa et al., 2001)- fue desbaratado por la violenta reestructuración multidimensional que vivió Chile a partir del Golpe de Estado de 1973. Según Kenneth Roberts (2002), este fenómeno -que se da en toda la región (latinoamericana) a consecuencia de la imposición del modelo neoliberal- presenta distintas características -y disímiles intensidades-, en los distintos países, según "la naturaleza del modo de articulación preexistente entre el sistema de partido y la sociedad".

En el caso de Chile, que desarrolló un "sistema de partido de movilización obrera de base clasista" 33 (Roberts, 2002), con nexos muy fuertes entre organizaciones políticas y sociales, donde la representación se estratificó -con bastante nitidez- en líneas de relación ideología-clase ${ }^{34}$, el impacto ocasionado por la irrupción militar, y todas las consecuentes transformaciones antes puntualizadas, resultó particularmente devastador. En especial para los partidos de izquierda ("obreristas"), que nacieron a la par de los movimientos obreros, y crecieron al ritmo de la industrialización, de la creación de empresas públicas, y la expansión de la burocracia estatal -y la correlativa multiplicación de trabajadores asalariados afiliados a asociaciones secundarias de gran escala- (Roberts, 2002). 
En el contexto neoliberal -postdictadura-, las condiciones que permitieron forjar estos fuertes lazos entre organizaciones políticas y sociales se volvieron desfavorables, o simplemente desaparecieron. En este sentido, Roberts (2002) -apoyándose en un informe de la Organización Internacional del Trabajo (1997)afirma que:

En tanto que las relaciones sociales han sido reestructuradas de acuerdo a principios de mercado, estas asociaciones secundarias han sido severamente debilitadas. Ha declinado el número relativo de trabajos estables en sectores de la economía fuertemente sindicalizados, como la industria de gran escala y los servicios públicos, mientras ha sido dramática la expansión de la fuerza de trabajo en la pequeña empresa y en los sectores informales, juntamente con una creciente dependencia de los contratos de trabajo temporarios (OIT, 1997). En mercados de trabajo tan precarios y fragmentados, los intereses e identidades heterogéneas de los trabajadores desincentivaron a las organizaciones colectivas. En conjunción con la represión política, han contribuido a una severa declinación de la sindicalización en la mayoría de los casos de movilización obrera. El debilitamiento de los sindicatos ha sido potenciado por la erosión de los patrones corporativos de representación de intereses, puesto que las reformas económicas han restringido la negociación colectiva, las garantías a la protección del trabajo y otros derechos laborales, con el objetivo de flexibilizar a los mercados laborales y reestructurar el espacio del trabajo a través de una base de contrato individual (p. 70-71).

En respuesta a esta nueva realidad -de "colectivismos segmentados de pequeña escala y mazas atomizadas" (Calderón y Jelin, 1987; Pásara y Zarzar, 1991 citados en Roberts, 2002), los partidos debieron amoldar sus estrategias de vinculación con el electorado, identificando a los electores «más como individuos que eligen libremente que como miembros de una comunidad de fieles" (Roberts, 2002). Por lo mismo, se vieron -y se ven- en la cada vez más difícil tarea de aglutinar -ya no en torno a proyectos monocromáticos "excluyentes" y claramente dirigidos- al complejo y variopinto "elector promedio", para lo cual han debido profesionalizar la actividad partidaria, recurriendo a las herramientas del marketing y a las nuevas tecnologías de las comunicaciones. Los partidos - producto de la creciente complejidad que implica la tarea de representar- dejaron de tener un rol importante como organizadores de la sociedad civil ${ }^{35}$, y pasaron a cumplir funciones netamente electorales, a raíz de lo cual «están más enredados en los circuitos de poder estatal y desvinculados de sus bases sociales" (Roberts, 2002).

\section{Reflexiones finales}

La idea inicial al emprender la labor de escribir este texto fue -como se señaló-, entregar algunos elementos para la construcción de una atalaya que permitiese observar el presente desde una mejor perspectiva, rescatando, para ello, y exponiendo -en forma somera- algunos hechos históricos que marcaron de cierta manera el discurrir del proceso de cambios experimentados por el Estado chileno y, particularmente, por la relación de este con aquella abstracción llamada nación.

Tal relación -Estado/nación-, como vimos, cobró un matiz distintivo durante la etapa de Industrialización por Sustitución de Importaciones, cuando el Estado jugó un papel central, tanto en la conducción de la economía -guiando el proceso de industrialización-, como en el ordenamiento de la sociedad -al distribuir beneficios, crear empleos, abrir espacios para la participación social, etc.-. En dicho contexto, las organizaciones políticas encontraron las condiciones propicias para entablar vínculos con organizaciones sociales vigorosas, en franco crecimiento, que tuvieron la virtud de encapsular a amplios grupos relativamente homogéneos- de electores motivados y movilizados por intereses comunes. Los partidos aprovechando las condiciones existentes- desarrollaron estrategias de articulación con sus bases de apoyo social (organizaciones sociales) cumpliendo la función de mediar entre el Estado -redistributivo-empresarioempleador- y la sociedad civil, ayudando a repartir beneficios y canalizando demandas.

El Golpe de Estado de 1973 marcó el fin de una era y el comienzo de otra; significó el término abrupto de un modelo -de Estado y de desarrollo económico- que si bien no aseguró estabilidad macroeconómica, ni disipó los conflictos políticos, ni llenó de dólares las arcas fiscales -a causa de la creciente (y tal vez desmedida) inversión fiscal-, sí consiguió incluir a vastos sectores de la población, otorgar un espacio y una voz a quienes antes no tenían dónde ni cómo hacer sentir su presencia, al tiempo que permitió el desarrollo de 
un sistema de partidos de amplio espectro, programática e ideológicamente rico y complejo, que, a pesar de la polaridad, logró mantenerse estable por cerca de medio siglo.

Las transformaciones impuestas por la dictadura militar -ideológicamente cargadas de neoliberalismo-, signaron el inicio de una etapa en la que el modelo de desarrollo Estado-céntrico fue sustituido por uno sustentado en el mercado, lo que ocasionó que el Estado abandonara el histórico rol de conductor-integradororganizador, para enfocar sus recursos y facultades en la tarea de generar y mantener las condiciones propicias para que se llevara a efecto el "libre" juego del mercado. A consecuencia de esto, los espacios y mecanismos que antes permitieron integrar y organizar a la sociedad fueron reducidos o del todo eliminados, provocando un distanciamiento en la relación Estado/nación, y generando -como parte de un proceso más amplio y complejo- atomización y dispersión social.

Al retomar la senda democrática, las organizaciones políticas debieron -sin tener muchas opciones, ni mucho "ánimo" para hacer algo distinto (a causa de las trabas sicológicas producidas por el quiebre de 1973)adaptarse a las nuevas condiciones propiciadas por el modelo heredado del gobierno militar. Por lo mismo, debieron rediseñar sus fórmulas de interacción con un electorado cada vez más disímil y micro-segmentado, profesionalizando las estrategias de identificación y captación de votantes, y recurriendo a las nuevas tecnologías de comunicación y a los medios de comunicación de masas. Consecuentemente, los partidos cumplen hoy una función netamente electoral y, a diferencia de lo ocurrido en la etapa del modelo Estadocéntrico, mantienen mínimos vínculos con las debilitadas organizaciones sociales de gran escala.

En tanto, la adaptación de las organizaciones políticas a las nuevas estructuras institucionales y a la nueva coyuntura, generó -como pudimos apreciar- una reducción del espectro político-ideológico intrasistema, a causa de los "consensos sustantivos", la "migración” desde posiciones "polares" hacia latitudes "ecuatoriales", y la exclusión - a los lindes exteriores del sistema- del partido y las fuerzas de izquierda contrarias al modelo imperante y a la ideología neoliberal.

Hoy se ha llegado a un punto en el que el marketing político y las campañas comunicacionales no bastan para vincular adecuadamente a ciudadanos y clase dirigente, en el que el estrecho espectro políticoideológico existente al interior del sistema no logra dar cuenta de la diversidad de intereses y miradas presentes en la cada vez más compleja sociedad nacional. Somos testigos de una profunda crisis de representación y de participación electoral, que se pone en evidencia con los bajos -y decrecientes- índices de asistencia ciudadana a las urnas, el alto rechazo a las autoridades, instituciones y organizaciones políticas, y la notoria incapacidad de los partidos de canalizar las demandas sociales. Esto último ha quedado de manifiesto con las recientes movilizaciones estudiantiles por un sistema educativo igualitario y de calidad, las mismas que se han desarrollado y -muy probablemente- se seguirán desarrollando a espaldas de los partidos y sin una participación relevante de actores políticos intra-sistema.

La actual coyuntura muestra la necesidad de repensar la institucionalidad política y el funcionamiento de los partidos. Si no se toman medidas oportunas veremos una peligrosa aceleración del proceso de disociación entre ciudadanía y representantes, con el consecuente deterioro del sistema democrático. Ver las cosas desde la perspectiva de la historia -cosa que proponemos en este trabajo- puede ayudar a entender de mejor manera el problema y a trazar algunas soluciones.

\section{Notas}

\footnotetext{
${ }^{1}$ Mediada por los partidos políticos.

${ }^{2}$ Ligado a estrategias de Industrialización por Sustitución de Importaciones (ISI) (Roberts, 2002).

${ }^{3}$ Crisis de la economía mundial con epicentro en Estados Unidos.
}

${ }^{4}$ Durante el gobierno del radical Pedro Aguirre Cerda (1938-1941), quien contó con el apoyo de la coalición de centro-izquierda llamada Frente Popular. 
${ }^{5}$ Producto de tales acuerdos se pudo establecer un marco institucional propicio para la industrialización. En este contexto se crea, en 1939, la Corporación de Fomento de la Producción (CORFO), “... que tuvo por objeto el desarrollo racional y armónico de todos los rubros productivos a lo largo del país" (Correa et al., 2001).

${ }^{6}$ Según la conceptualización de Raúl Prebisch: el poder sindical está relacionado a la capacidad, de aquella fuerza de trabajo que no es favorecida por las leyes del mercado, de acrecentar su remuneración conforme aumenta la productividad (Prebisch, 1981; Di Filippo, 2006).

${ }^{7}$ Sindicatos u otras organizaciones. A decir de Correa et al (2001), el Estado fue atendiendo progresivamente las demandas de los distintos grupos sociales -organizaciones sociales como las concibe D. North (Prado, 1998)-, en función a sus propias capacidades para ejercer presiones y articularse con los partidos políticos.

${ }^{8}$ Las que permitieron la participación de mujeres y analfabetos en los comicios. Además de esto eliminaron la exigencia de inscripción periódica en los registros electorales y las penas de prisión por abstención electoral. Entre 1957 y 1969 el electorado creció en un 350\%, de 1,28 millón a 3,24 millones (Fontaine, 1993).

${ }^{9}$ Recordando el lema “todo tiene que cambiar”, usado por Frei Montalva en la campaña del 1964 (Fontaine, 1993).

10 “... el objetivo principal de las intervenciones gubernamentales se desplazó gradualmente desde una mera apropiación de una parte de las rentas generadas por las distintas actividades económicas hacia la expropiación de los activos que producían esas rentas" (Fontaine, 1993).

${ }^{11}$ Que según Tomic permitiría a la Democracia Cristiana permanecer en el poder por al menos 30 años (Correa et al., 2001).

${ }^{12}$ El parlamento se vio especialmente debilitado como espacio para el debate y la suscripción de acuerdos (Correa et al., 2001).

${ }^{13}$ Esto se demuestra con la fuerte lucha que se llevó a cabo entre la Democracia Cristiana y los partidos de izquierda por el control de los sindicatos (Correa et al., 2001).

${ }^{14}$ La Democracia Cristiana (DC) “... surgió en 1958 de la fusión de la Falange Nacional, los conservadores social cristianos y políticos que habían apoyado a Ibañez entre 1952 y 1958” (Moulián, 2002). Según afirma Moulián (2002) nació como una organización católica de orientación progresista.

${ }^{15}$ El programa de "Promoción Popular" impulsado por el gobierno de Frei logró, a través del fortalecimiento de sindicatos obreros, la creación de sindicatos campesinos, así como la extensión y vigorización de otros mecanismos de articulación social -juntas de vecinos, asociaciones de padres de familia, etc.- ampliar la participación social en el debate y en la acción política nacional.

${ }^{16}$ En especial del Ejecutivo, en desmedro del Legislativo que fue perdiendo la capacidad de encausar y articular el debate político, antes concentrado en los grupos parlamentarios y ahora extendido a amplios sectores sociales (Correa et al., 2001).

${ }^{17}$ La que en parte culminaría con la definitiva separación de un importante grupo de la Juventud Demócrata Cristiana, que formó, en 1969, el Movimiento de Acción Popular Unitaria (MAPU). El MAPU se sumaría luego a las fuerzas de izquierda reunidas en la Unidad Popular (Correa et al., 2001).

${ }^{18}$ La campaña presidencial de 1970 fue un reflejo fiel del contexto socio-político. Los representantes de los tres sectores ideológicos Jorge Alessandri por la derecha (Independiente), Radomiro Tomic por el centro (DC) y Salvador Allende por la izquierda (UP)- se enfrascaron en arduas disputas en torno a cómo se debía enfrentar la compleja realidad nacional, teniendo cada uno de ellos particulares y excluyentes fórmulas y proyectos de futuro. Al final del proceso, a pesar de los temores y las maquinaciones -internas y externas 18-, Salvador Allende, representante de la izquierdista alianza Unidad Popular (UP), ganó la presidencia con el 36,3\% de las preferencias, frente al 34,9\% de Alessandri y el 27,8\% de Tomic (Correa et al, 2001). Tal como lo establecía la Constitución -debido a que ninguno de los candidatos obtuvo sobre el 50\%- el Congreso de la República debió definir la contienda entre las dos más altas mayorías. Esta instancia se tornó en un nuevo escenario para las confrontaciones, las presiones en uno y otro sentido y las manifestaciones violentas. En definitiva, gracias al apoyo -condicionado- de la Democracia Cristiana, el Congreso ratificó el triunfo de la Unidad Popular, y Allende asumió la primera magistratura de la nación.

${ }^{19}$ Legislación que tipificaba las causales de expropiación, originada durante la República Socialista de 1932 (Correa et al, 2001).

${ }^{20}$ Al ser la baja productividad causal de expropiación, muchos trabajadores recurrieron a las huelgas y tomas para precipitar la intervención estatal. En el ámbito rural, muchas tomas de terrenos y fundos fueron apoyadas por los sectores más radicales de la Unidad Popular (UP) y por militantes del Movimiento de Izquierda Revolucionaria (MIR) (Correa et al., 2001).

${ }^{21}$ René Schneider (1913-1970), fue comandante en jefe del Ejército nombrado por el presidente Frei. "Su posición inclaudicable, resumida en que los militares no podían intervenir en asuntos políticos y debían un respeto irrestricto a la Constitución, pasó a ser conocida como la Doctrina Schneider" (Correa et al., 2001).

22 "Estado empresario" y “empleador" (Garretón, 1995).

${ }^{23}$ Con la entrada al ruedo de los llamados "Chicago boys" -grupo de jóvenes economistas chilenos egresados de la Universidad de Chicago, que confluyeron en altos cargos del gobierno militar, y que promovieron en forma férrea el libre mercado (Fontaine, 1993)-. 
24 “... tanto en lo que se refiere a los mercados laborales como a los salarios" (Garretón, 1995).

${ }^{25}$ Consumidores "libres" -en la medida de las (siempre desiguales) posibilidades individuales-, pero ciudadanos con derechos restringidos.

${ }^{26}$ Sobre la "naturalización" de las leyes de mercado, ver El mito del desarrollo: Los países inviables del siglo XXI, de Oswaldo de Rivero (2001).

${ }^{27}$ En el marco de una guerra ideológica planetaria -y galáctica, recordando a Reagan- contra el bloque soviético y el marxismo internacional.

${ }^{28} \mathrm{El}$ “... triunfo cultural del individualismo, que inhibe las formas más orgánicas y solidarias de expresión y de acción colectiva", y el “... cambio acelerado [...] de la sociedad chilena, (que) complica su representación...” (Micco, Saffiro, 2000).

${ }^{29}$ El fin de la historia proclamado por Fukuyama (1990).

${ }^{30}$ Sobre el sistema electoral binominal, ver El sistema de partidos en Chile, de Tomás Moulián. en Cavarozzi y Abal Medina (comp.) 2002 .

${ }^{31}$ Ver Correa et al., 2001 y Moulián 2002.

${ }^{32}$ Delimitaciones establecidas por la normativa vigente según North (1981 citado en Prado, 1998). En este caso la Constitución de 1980 y el sistema electoral.

${ }^{33}$ Donde “... la movilización de los trabajadores fue guiada por los partidos marxistas o movimientos revolucionarios que eclipsaron a los partidos tradicionales de la oligarquía, polarizando severamente el espectro político a lo largo de líneas de clase”. (Roberts, 2002).

34 “... la clase trabajadora tendió a votar por los partidos Socialistas o Comunistas, la clase media se inclinó más hacia los partidos de centro, y los sectores de la élite (y, con anterioridad a los años 60 ‘s, los pobres rurales) optaron marcadamente por los partidos conservadores pro-financieros. (Aldunate, 1985 citado en Roberts, 2002).

${ }^{35}$ Siendo reemplazados por "una diversidad de grupos de interés, movimientos sociales y organizaciones no-gubernamentales" (Roberts, 2002).

\section{Bibliografía}

Castells, M. (2005), Globalización, desarrollo y democracia: Chile en el contexto mundial. Fondo de Cultura Económica, Chile.

Correa, S. et al. (2001), Historia del siglo XX chileno. Editorial Sudamericana, Santiago.

Di Filippo, A. (2006), Políticas del desarrollo en América Latina (“Apunte de clases”). Magíster ESPO. UAH, Santiago.

Fontaine, J. A. (1993), “Transición económica y política en Chile: 1970-1990”. Estudios Públicos, 50, 229-279.

Fukuyama, F. (1990), “¿El fin de la historia?”, Estudios Públicos, 37, 5-31.

Garretón, M. A. (1995), Hacia una nueva era política. Fondo de Cultura Económica, Chile.

Ídem (2003), “La democratización incompleta y los desafíos del futuro”. Vanguardia Dossier, 4, 75-77.

Gilbert, J. (1997), "De la vía chilena al socialismo al modelo neoliberal de libre mercado". Center for Latin American Studies, 61-81.

González, A. (2001), "La transición democrática en Chile: reubicación de las fuerzas armadas y repercusiones andinas". En CAJ, Los problemas de la democracia en la región andina: Mecanismos de defensa y procesos de transición (p. 45-71). Comisión Andina de Juristas, Lima.

Moulián, T. (2002), El sistema de partidos en Chile. En Cavarozzi, M. y Abal Medina, J. M. (comp.), El asedio a la política. (p. 241-257). Rosario: Homo Sapiens Ediciones.

Prado, G. (1998, septiembre), “El pensamiento económico de Douglass C. North”, Laissez-Faire, 9, 13-32.

Prebisch, R. (1981), Capitalismo periférico, crisis y transformación. Fondo de Cultura Económica, México. 
Roberts, K. (2002), "El sistema de partidos y la transformación de la representación política en la era neoliberal latinoamericana". En Cavarozzi, M. y Abal Medina, J. M. (comp.), El asedio a la política. (p. 55-76). Homo Sapiens Ediciones, Rosario.

Vidal, J. M. (1999), “Dos versiones de la mundialización: George Soros y Samir Amin”. Tendencias, 1-9. 